\title{
PEMANFAATAN APLIKASI KALKULATOR FISIKA UNTUK MENINGKATKAN MOTIVASI BELAJAR PADA MATERI FISIKA GERAK
}

\author{
Siwi Puji Astuti \\ Teknik Informatika, Universitas Indraprasta PGRI \\ Email: siwiunindra2012@gmail.com
}

\begin{abstract}
Abstrak
Tujuan dari penelitian ini untuk meningkatkan motivasi belajar mahasiswa menggunakan Matlab. Penelitian dilaksanakan pada mahasiswa program studi Teknik Informatika, fakultas FTIK Universitas Indraprasta PGRI. Populasi dari penelitian ini adalah mahasiswa Teknik Informatika semester 3 pada semester gasal tahun ajaran 2020/202. Sampel yang diambil dalam penelitian menggunakan teknik sampel bertujuan atau purposive sample. Pengumpulan data dilakukan dengan cara menghitung hasil angket motivasi belajar menggunakan Matlab. Berdasarkan perhitungan didapat skor sebesar 80,81\%, atau dapat dikatakan bahwa mahasiswa yang suka belajar fisika dengan matlab sebanyak 59,8 atau dibulatkan menjadi mahasiswa dari 60 mahasiswa dari 74 mahasiswa yang artinya sebanyak 60 mahasiswa setuju dengan adanya penggunaan software Matlab membuat mahasiswa lebih memahami materi fisika gerak.
\end{abstract}

Kata Kunci : Motivasi Belajar, Fisika Gerak, Matlab

\section{Abstract}

The purpose of this study is to increase students learning motivation using Matlab. The research was carried out on students of the Informatics Engineering study program, Faculty of FTIK, Indraprasta University, PGRI. The population of this study were the 3rd semester Informatics Engineering students in the odd semester of the 2020/2021 school year. The sample taken in the study used purposive sampling technique. The data were collected by calculating the results of the questionnaire on learning motivation using Matlab. Based on the calculation, the score obtained was $80.81 \%$, or it can be said that students who like to study physics with Matlab were 59.8 or rounded up to 60 students out of 74 students, which means 60 students agreed with the use of Matlab software to make students better understand physics material of motion.

Key Words : Learning Motivation, Motion Physics, Matlab

\section{PENDAHULUAN}

Mata kuliah fisika merupakan mata kuliah yang mengajarkan berbagai pengetahuan yang dapat mengembangkan daya nalar dan analisa. Sehingga hampir semua permasalahan yang berkaitan dengan alam dan sekitarnya membutuhkan kemampuan dalam memahami konsep fisika. Penggunaan media pembelajaran juga dapat menentukan motivasi belajar dalam proses pemahaman konsep fisika. Untuk itu diperlukan inovasi pembelajaran berbasis teknologi agar gaya belajar menjadi lebih menarik perhatian mahasiswa terlebih lagi dalam kondisi kuliah daring yang disebabkan oleh pandemi Covid-19 membuat motivasi belajar fisika mahasiswa berkurang.

Pembelajaran berbasis teknologi memberikan kemudahan dalam bidang pendidikan. Kehadirannya memberikan dampak positif dan sangat berguna sekali terlebih lagi dalam menjalani pembelajaran secara daring seperti ini. Banyak sekali media pembelajaran online atau platform pembelajaran yang tentunya semua itu sebagai upaya untuk meningkatkan motivasi belajar, minat belajar, dan bahkan prestasi belajar di tengah kondisi pandemi ini. 
Banyak juga program aplikasi komputer yang bisa dimanfaatkan sebagai media pembelajaran fisika khususnya materi fisika gerak. Salah satunya matrix laboratory atau yang dikenal dengan sebutan Matlab. Matlab sangat cocok digunakan untuk aplikasi Sains, karena memiliki hasil yang akurat dibandingkan menghitung secara manual. Selain itu Matlab juga memiliki kemampuan grafis yang sangat baik.

Matlab adalah suatu software yang dapat membantu kita untuk melakukan perhitungan matematik, analisis data, mengembangkan algoritma, melakukan simulasi dan pemodelan, serta menyajikannya dalam bentuk grafis [1]. Sedangkan menurut Sianipar menyatakan bahwa matlab dapat digunakan untuk menyelesaikan permasalahan matematis dan alat bantu dalam proses pembelajaran [2].

Pemanfaatan dan penggunaan software Matlab pada fisika gerak dapat menambah variasi dalam proses pembelajaran fisika, sehingga pemanfaatannya diharapkan dapat membantu mahasiswa dalam memahami rumus-rumus fisika kinematika terutama dalam menyelesaikan soal-soal fisika kinematika [3]. Karena kemampuan mahasiswa dalam memahami soal-soal fisika masih sangat rendah. Kemampuan memahami soal dimaksudkan sebagai soal yang diberikan secara teori dan belum mampu dikerjakan oleh mahasiswa kemudian dikerjakan kembali setelah diketahui hasilnya dengan bantuan software Matlab [4].

Salah satu materi fisika gerak adalah aplikasi hukum Newton pada sistem katrol. Pada sistem benda inilah banyak berlaku hukum II Newton. Untuk menganalisa permasalahan sistem benda yang berkaitan dengan gaya dapat menggunakan hukum II Newton. Tujuan dari penelitian ini untuk meningkatkan motivasi belajar mahasiswa menggunakan Matlab. Selain itu penelitian ini digunakan sebagai salah satu referensi dalam menambah variasi dalam proses pembelajaran.

\section{METODE}

Penelitian dilaksanakan pada mahasiswa program studi Teknik Informatika, fakultas FTIK Universitas Indraprasta PGRI. Populasi dari penelitian ini adalah mahasiswa Teknik Informatika semester 3 pada semester gasal tahun ajaran 2020/2021. Dan yang menjadi sampel penelitian adalah mahasiswa Teknik Informatika kelas Y3K sebanyak 36 mahasiswa dan Y3L sebanyak 38 mahasiswa, sehingga total sampel penelitian sebanyak 74 mahasiswa. Sampel yang diambil dalam penelitian ada dua kelas yaitu kelas Y3K dan Y3L yang merupakan kelas diajar oleh peneliti dengan menggunakan teknik sampel bertujuan atau purposive sample, yaitu pengambilan sampel bukan didasarkan pada strata, random, atau daerah tetapi didasarkan atas adanya tujuan tertentu.

Pengumpulan data dilakukan dengan cara menghitung hasil angket motivasi belajar menggunakan Matlab yang disebarkan kepada mahasiswa Y3K dan Y3L melalui link google form https://forms.gle/4rHT3Vcd8PGAMEPx5 untuk mengetahui besar motivasi mahasiswa dalam belajar fisika gerak. Pengolahan data dilakukan dengan menggunakan statistika deskriptif.

\section{HASIL DAN PEMBAHASAN}

Proses pembelajaran fisika yang dilakukan secara daring dimulai dengan pembahasan materi beserta rumus-rumus fisika terlebih dahulu dan diberikan contoh-contoh soal 
yang berkaitan dengan materi fisika. Setelah itu dilanjutkan dengan praktek menggunakan software Matlab secara bersama-sama melalui zoom meeting. Dalam penelitian ini mahasiswa diharuskan membuat kalkulator fisika sederhana menggunakan software Matlab dalam setiap pokok bahasan fisika gerak yang diberikan.

Dalam membuat rumus fisika menggunakan software Matlab mahasiswa diharapkan akan lebih memahami rumusrumus fisika yang sudah dipelajari. Karena mahasiswa dituntut untuk dapat mengerjakan soal-soal fisika secara manual maupun mengerjakan soal-soal fisika dengan menggunakan software matlab. Dengan demikian pemanfaatan software Matlab dapat meningkatkan motivasi belajar mahasiswa dalam proses pembelajaran fisika gerak.

Berikut adalah contoh perhitungan manual dari contoh soal aplikasi hukum Newton [5].

Contoh Soal:

Balok $\mathrm{A}=3 \mathrm{~kg}$ diletakkan di atas meja kemudian diikat tali yang dihubungkan batu $\mathrm{B}=2 \mathrm{~kg}$ melalui sebuah katrol seperti pada Gambar. Massa dan gesekan katrol diabaikan, $\mathrm{g}=10 \mathrm{~m} / \mathrm{s} 2$. Tentukan percepatan sistem dan tegangan tali jika: a. meja licin, b. meja kasar dengan koefisen gesek kinetik $\mu \mathrm{k}=0,4$ !

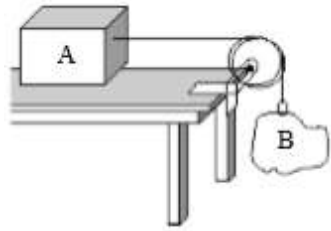

\section{Penyelesaian}

Diketahui: $\mathrm{m}_{\mathrm{A}}=3 \mathrm{~kg} \rightarrow \mathrm{w}_{\mathrm{A}}=30 \mathrm{~N}$

$$
\begin{aligned}
\mathrm{m}_{\mathrm{B}} & =2 \mathrm{~kg} \rightarrow \mathrm{w}_{\mathrm{B}}=20 \mathrm{~N} \\
\mathrm{~g} & =10 \mathrm{~m} / \mathrm{s}^{2}
\end{aligned}
$$

Ditanya:

a. a dan T, jika meja licin?

b. a dan $\mathrm{T}$, jika meja kasar?

Jawab

a. Meja Licin

Jika meja licin maka gaya-gaya yang bekerja pada balok dan batu

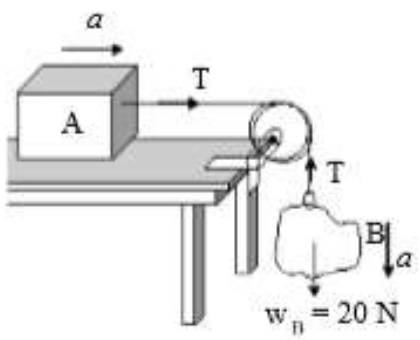

Pada balok A : $\quad \mathrm{T}=\mathrm{mA} \cdot \mathrm{a}$

Pada batu $B: w B-T=m_{B} \cdot a$

Sehingga $\quad T=3 \cdot a$

$$
\frac{20-\mathrm{T}=2 \cdot \mathrm{a}+}{20=5 \mathrm{a}}
$$

Berarti percepatannya : $a=4 \mathrm{~m} / \mathrm{s}^{2}$

Dan tegangan tali memenuhi:

$\mathrm{T}=3 \mathrm{a}=3.4=12 \mathrm{~N}$

\section{b. Meja Kasar}

Jika meja licin maka gaya-gaya yang bekerja pada balok dan batu

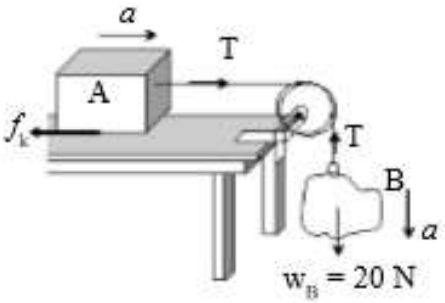

$$
\begin{aligned}
& \mu \mathrm{k}=0,4 \\
& \mathrm{fk}=\mu \mathrm{k} \cdot \mathrm{N}_{\mathrm{A}}=0,4 \cdot 30=12 \mathrm{~N}
\end{aligned}
$$

Pada balok A : $\quad \mathrm{T}-\mathrm{fk}=\mathrm{mA} \cdot \mathrm{a}$

Pada batu $B: w B-T=m_{B} \cdot a$

Sehingga $T-12=3 \cdot a$

$$
\begin{gathered}
20-\mathrm{T}=2 \cdot \mathrm{a}+ \\
8=5 \mathrm{a}
\end{gathered}
$$


Berarti percepatannya : $a=1,6 \mathrm{~m} / \mathrm{s}^{2}$

Dan tegangan tali memenuhi:

$\mathrm{T}-\mathrm{fk}=3 \cdot \mathrm{a}$

$\mathrm{T}-12=3 \cdot 1,6$

$\mathrm{T}=16,8 \mathrm{~N}$

Kemudian mahasiswa akan membuat contoh kalkulator fisika dari aplikasi hukum newton dan menghitung dengan menggunakan matlab dari contoh yang sebelumnya dihitung secara manual, seperti pada gambar,

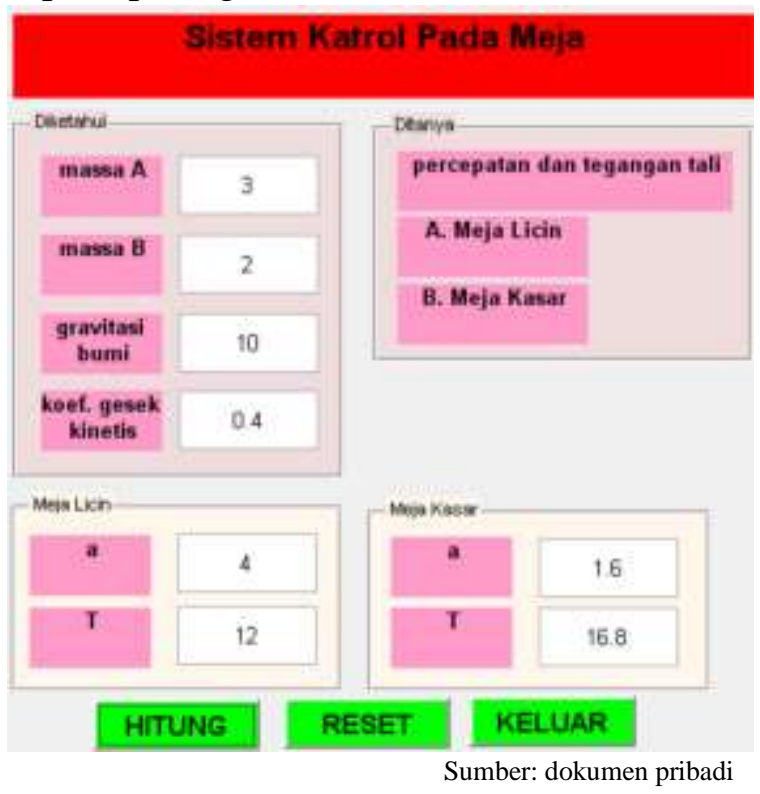

Gambar 1. Tampilan GUI Matlab untuk Aplikasi Hukum Newton

Setelah selesai mendesain tampilan GUI Matlab, langkah selanjutnya adalah memperhatikan fungsi yang memiliki callback, ada tombol hitung, tombol reset, dan tombol keluar.

- Untuk tombol Hitung

Klik kanan tombol hitung $\rightarrow$ view callback $\rightarrow$ callback Ketikkan kode-kode seperti terlihat dalam gambar di bawah ini,

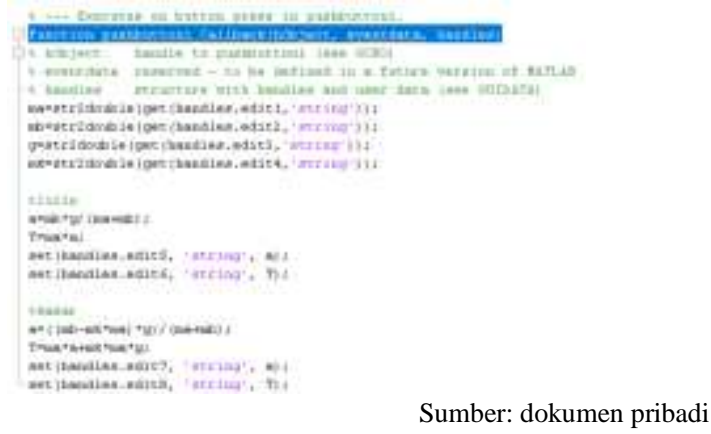

\section{Gambar 1. Sintak Program Tombol Hitung}

- Untuk tombol reset dan keluar

Klik kanan tombol hitung $\rightarrow$ view

callback $\rightarrow$ callback Ketikkan kode-kode seperti terlihat dalam gambar di bawah ini,

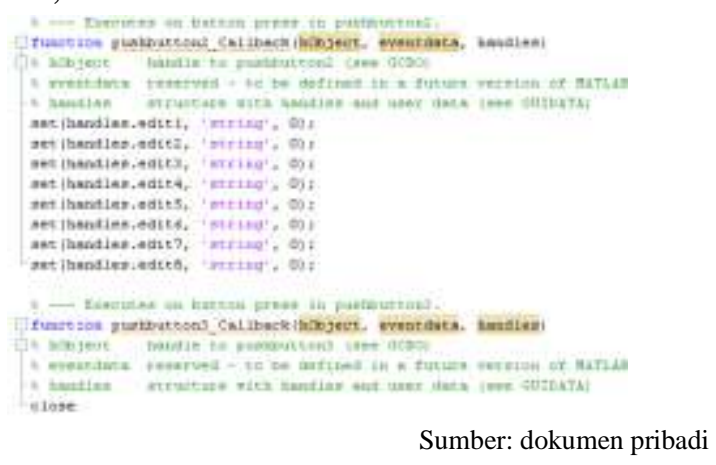

\section{Gambar 1. Sintak Program tombol Reset dan Keluar}

Kalkulator fisika ini sangat cocok untuk digunakan dalam pembelajaran fisika baik ditingkat SMA/SMK dan perguruan tinggi [6]. Selain untuk menambah wawasan, kalkulator ini dapat meminimalisir kesalahan perhitungan.

Untuk mengetahui seberapa besar motivasi belajar fisika, maka penulis menyebarkan angket kepada mahasiswa yang menjadi sampel penelitian ini, yaitu mahasiswa Y3K dan Y3L. Penilaian menggunakan skala likert, dimana penilaian dengan skala 1 - 5 dinyatakan oleh jumlah mahasiswa (1=sangat tidak suka, $2=$ tidak suka, $3=$ netral, $4=$ suka, $5=$ sangat suka). 
Tabel 1. Angket Motivasi Belajar Menggunakan Matlab

\begin{tabular}{|c|c|c|c|c|c|c|}
\hline \multirow{2}{*}{ No. } & \multirow{2}{*}{$\begin{array}{c}\text { Aspek } \\
\text { penilaian }\end{array}$} & \multicolumn{5}{|c|}{ Penilaian } \\
\hline & & 5 & 4 & 3 & 2 & 1 \\
\hline 1. & $\begin{array}{l}\text { Belajar fisika } \\
\text { dengan Matlab } \\
\text { dapat } \\
\text { menumbuhkan } \\
\text { motivasi belajar } \\
\text { saya. }\end{array}$ & 26 & 29 & 16 & 2 & 1 \\
\hline 2. & $\begin{array}{l}\text { Software matlab } \\
\text { membuat saya } \\
\text { lebih memahami } \\
\text { soal fisika } \\
\text { sehingga saya } \\
\text { jadi termotivasi } \\
\text { untuk terus } \\
\text { belajar fisika. }\end{array}$ & 22 & 32 & 13 & 7 & 0 \\
\hline 3. & $\begin{array}{l}\text { Saya memiliki } \\
\text { kesulitan belajar } \\
\text { fisika dengan } \\
\text { menggunakan } \\
\text { matlab sehingga } \\
\text { saya kurang } \\
\text { termotivasi. }\end{array}$ & 8 & 9 & 17 & 20 & 20 \\
\hline 4. & $\begin{array}{lr}\text { Belajar } & \text { fisika } \\
\text { tidak } & \text { cukup } \\
\text { dengan } & \text { teori } \\
\text { saja } & \text { sehingga } \\
\text { perlu } & \text { media } \\
\text { belajar } & \text { seperti } \\
\text { Matlab. } & \end{array}$ & 40 & 18 & 15 & 0 & 1 \\
\hline 5. & $\begin{array}{l}\text { Soal-soal fisika } \\
\text { sangat sulit } \\
\text { untuk dipahami. }\end{array}$ & 10 & 15 & 17 & 24 & 8 \\
\hline
\end{tabular}

Sebelum menyelesaikan perhitungan, kita harus membuat interval dan interpretasi persen agar mengetahui penilaian dengan metode mencari interval skor persen interval.

$$
\text { Interval }=\frac{100}{5}=20
$$

Berikut kriteria interpretasi skor perhitungan berdasarkan interval :

- $\quad 0 \%-19,99 \%=$ sangat tidak setuju

- $20 \%-39,99 \%=$ tidak setuju

- $40 \%-59,99 \%=$ netral

- $60 \%-79,99 \%=$ setuju

- $\quad 80 \%-99,99 \%=$ sangat setuju
Berdasarkan Tabel, pada bagian no 1 diperoleh total skor berjumlah 299 dari jumlah skor tertinggi secara keseluruhan berjumlah 370 .

Sehingga perhitungan pada bagian no.1 didapat

Rumus indeks $\%=\frac{\text { Total skor }}{\mathrm{Y}} \times 100$

Rumus indeks $\%=\frac{299}{370} \times 100=80,81 \%$

Berdasarkan perhitungan tabel pada bagian no 1 didapat skor sebesar $80,81 \%$, atau dapat dikatakan bahwa mahasiswa yang suka belajar fisika dengan matlab sebanyak 59,8 atau dibulatkan menjadi mahasiswa dari 60 mahasiswa dari 74 mahasiswa. Dengan menggunakan perhitungan yang sama, pada bagian no 2 menunjukkan hasil $78,65 \%$ yang artinya sebanyak 58 mahasiswa setuju dengan adanya penggunaan software Matlab membuat mahasiswa lebih memahami soal fisika gerak.

Penelitian yang berhubungan dengan pemanfaatan software Matlab dilakukan oleh Hendra Kartika [7] Tujuan dari penelitian yang dilakukan oleh Hendra Kartika adalah untuk melihat pengaruh pembelajaran matematika berbantuan software matlab sebagai upaya meningkatkan kemampuan komunikasi matematis dan minat belajar siswa SMA. Penelitian lain yang berhubungan yaitu penelitian yang menyatakan bahwa Ada Pengaruh Media Pembelajaran Matrix Laboratory (MATLAB) Terhadap Hasil Belajar Siswa Kelas VII Pada Mata Pelajaran Matematika di SMP Negeri 5 
Kopang kabupaten Lombok Tengah Tahun Pelajaran 2017/2018 [8].

Salah satu penerapan kalkulator fisika menggunakan software Matlab yaitu untuk materi dinamika gerak sistem katrol berbasis Matlab [9]. penggunaan GUI untuk dinamika gerak sistem katrol membuat lebih efektif karena disertakan berupa gambaran visual mengenai gerak sistem yang sesuai dengan input yang akan digunakan. Penerapan kalkulator fisika untuk analisis ayunan matematis juga dapat digunakan sebagai media pembelajaran dan alat bantu analisis ayunan matematis [10]. Penggunaan kalkulator fisika berbasis matlab selain meminimalisir kesalahan hitung juga dapat menghemat waktu saat melakukan analisis ayunan matematis.

Berdasarkan pengamatan penulis selama menjelaskan materi dan rumus-rumus fisika beserta contoh soalnya mahasiswa jarang ada yang bertanya. Berbeda saat penulis menjelaskan materi dengan menggunakan Matlab, mahasiswa cenderung lebih aktif bertanya sehingga membuat suasana kelas menjadi hidup dan tidak monoton.

\section{SIMPULAN}

Berdasarkan hasil perhitungan angket motivasi belajar mahasiswa menggunakan Matlab didapat skor sebesar $80,81 \%$ yang menyatakan bahwa sebanyak 60 mahasiswa dari 74 mahasiswa suka belajar fisika dengan menggunakan software Matlab. Maka dapat disimpulkan bahwa software Matlab dapat meningkatkan motivasi belajar fisika gerak.

\section{DAFTAR PUSTAKA}

[1] R. Y. Hutahaean, Pemrograman
Matlab untuk Mahasiswa, 1st ed. Yogyakarta: ANDI, 2018.

[2] M. D. Nasution, E. Nasution, dan F. Haryati, "Pengembangan Bahan Ajar Metode Numerik dengan Pendekatan Metakognitif Berbantuan MATLAB," J. MOSHARAFA, vol. 6, no. 1, pp. 69-80, 2017, doi: 10.31980/mosharafa.v6i1.295.

[3] S. P. Astuti dan T. W. Alhidayatuddiniyah, "Pemanfaatan Software Matrix Laboratory (Matlab) untuk Meningkatkan Minat Belajar Mahasiswa dalam Pembelajaran Fisika Kinematika," J. Pendidik. Berkarakter, vol. 3, no. 2, pp. 54-57, 2020, doi: 10.31764/pendekar.v3i2.2892.

[4] G. Widosari, "Kontribusi Pendidikan Matematika dan Matematika dalam Membangun Karakter Guru dan Siswa," in Penggunaan Software Matlab untuk Meningkatkan Minat Belajar Matematika di Politeknik Negeri Samarinda, 2012, p. P-37.

[5] D. Parwatiningtyas, dkk, Fisika Dasar, 2nd ed. UNINDRA PRESS, 2018.

[6] I. Y. Okyranida, F. Widiyatun, dan D. A. S. Asih, "Perancangan Aplikasi Kalkulator Fisika pada Materi Gaya Newton," J. Inov. Penelit., vol. 1, no. 8, pp. 16631668, 2021, doi: 10.47492/jip.v1i8.297.

[7] H. Kartika, "Pembelajaran Matematika Berbantuan Software MATLAB sebagai Upaya Meningkatkan Kemampuan Komunikasi Matematis dan Minat Belajar Siswa SMA," J. Pendidik. UNSIKA, vol. 2, no. 1, pp. 24-35, 2014.

[8] A. MS dan M. H. Baysha, "Pengaruh Media Pembelajaran MATRIX LABORATORY (MATLAB) terhadap Hasil Belajar Siswa," $J$. Teknol. Pendidik., vol. 3, no. 2, pp. 
10-20, 2018, doi: 10.33394/jtp.v0i2.1235.

[9] A. M. Nugraha, "Graphic User Interface (GUI) untuk Materi Dinamika Gerak Sistem Katrol Berbasis Matlab," J. Navig. Phys., vol. 1, no. 2, pp. 51-58, 2019, doi: 10.30998/npjpe.v1i2.200.

[10] Nurullaeli dan I. A. D. Astuti, "Pembuatan Graphic User Interface (GUI) untuk Analisis Ayunan Matematis Menggunakan Matlab," $J$. Ilm. Multi Sci., vol. 10, no. 2, pp. 4856, 2018, doi: 10.30599/jti.v10i2.205. 